\title{
Research on the microenvironment intelligent control system of cultural relics protection
}

\author{
Ying Zhong ${ }^{1, a^{*}}$, Yang Zhang ${ }^{2, b}$ and Hui Zhang ${ }^{3, c}$ \\ ${ }^{1}$ School of Instruments Science and Opto-electronics Engineering, Hefei University of Technology, \\ Hefei 230009, China \\ ${ }^{2}$ School of Instruments Science and Opto-electronics Engineering, Hefei University of Technology, \\ Hefei 230009, China \\ ${ }^{3}$ Hefei University of Technology, Hefei 230009, China \\ azoeyz910623@163.com, byzhang0615@163.com, czhanghui-nano@126.com
}

Keywords: Cultural Relic protection, Microenvironment control, Constant temperature and humidity equipment, Air purifying equipment, Lighting control equipment.

Abstract. The microenvironment control in museum is the most important part in the protection of cultural relics. Aimed at the control of the microenvironment of cultural relics, in this paper, a new microenvironment control system is established which achieves the unified regulation of the microenvironment of cultural relics through the combination of temperature and humidity control, air quality control, light control and security measures. This paper mainly introduces the establishment and application of the microenvironment intelligent control system on the basis of integration and free maintenance. Besides, several examples presented in the paper verify the feasibility and validity of the system which makes the control of the microenvironment of cultural relics rise to a new level and will surely have a promising future.

\section{Introduction}

China is one of the world's ancient civilizations. She has a long history and rich cultural heritage. In order to preserve these cultural relics better for the development and utilization of information resources stored in them, we must protect the cultural heritage as a form of physical form, in order to make them to serve longer for the development of human civilization service [2]. The primary task of the protection of cultural relics is to control the environment to minimize the speed of heritage materials aging and deterioration caused by environmental factors [1]. Therefore, the control of heritage preservation museum environment occupies a very important position in the development of the museum. Most of the domestic museum environment monitor means is based on the main traditional manual inspection. This regulatory approach not only greatly reduces the timeliness, but also increases the labor intensity and maintenance costs. Few people use digital sensors to detect the environment and use wireless communication mode to transmit and manage information. But in the control of the microenvironment of cultural relics this approach has some problems, for example low precision, poor stability, short duration of effective action, slow response to the external environment and so on. Therefore, the combination of the digital monitoring tools, wireless networking communication means and electronic control method which form a wireless networking microenvironment monitoring systems, is the rapid development direction of the country currently.

\section{The architecture of microenvironment intelligent control system}

There are many Factors affecting microenvironment of the cultural relics protection, temperature, humidity, light, air cleanliness, mold, worms and so on [4]. In different factors and cultural relic textures, the sensitivity of cultural relic is also different. The main factors leading to cultural relic damage are humidity, nitrogen sulfide, ozone, light, particulate matter, and so on. Based on the above considerations, establish the system of cultural relic microenvironment, shown in Figure 1, the 
system consists of five parts: thermostat, humidistat, air purifying equipment, lighting control equipment, wireless security equipment.

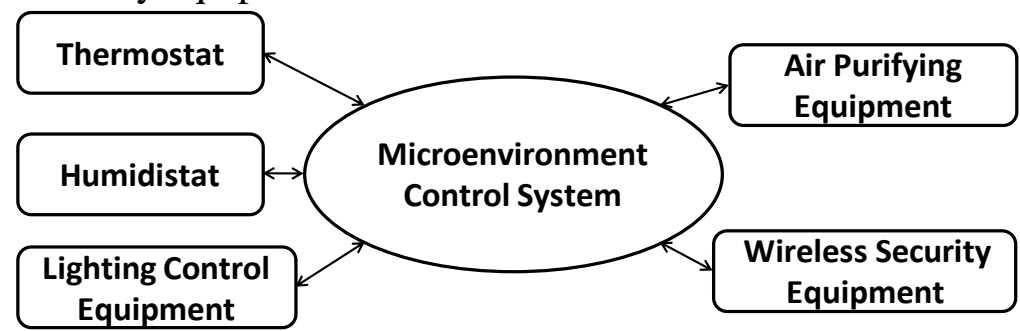

Fig.1 Architecture of microenvironment intelligent control system

\section{Case study: microenvironment humidity control}

The system structure of microenvironment humidity control equipment is shown in Figure 2 . When the system is working, the show case inlet exhausts gas which has been humidified, and the gas filling the interior space of show case from top to bottom. With effect of showcase under positive pressure and the main fan of control, relatively dry gas get into the humidistat through the outlet, and the air in showcase interior and the humidistat gas are mixed. So on ad infinitum, the system realized the humidification function ultimately. Dehumidification process is in the same way.

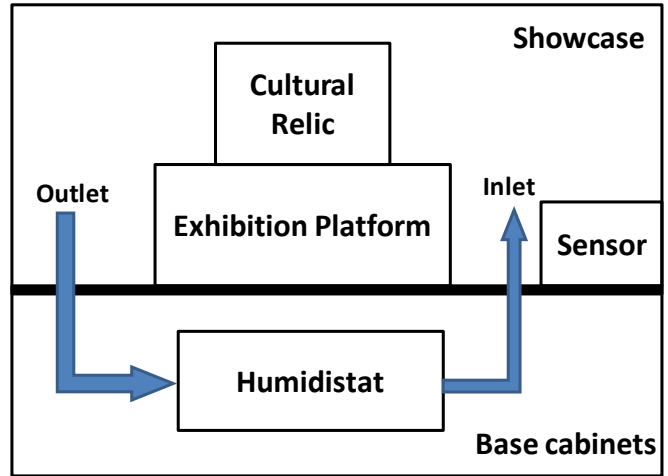

Fig.2 Overall system configuration diagram of humidistat

The hardware schematic diagram of humidistat is shown in Figure 3. Temperature and humidity sensors measure temperature and humidity data near the outlet in the showcase, and transmitted them to the master controller (using MC9S12XS128 SCM). The gas in show case get into the interior of humidistat with effect of the main fan. The main controller compares the humidity data from the sensor with the target value of humidity, and calculates the corresponding amount of humidity control. By adjusting refrigerating capacity of the semiconductor chilling plate, the gas flowing through is humidified or dehumidified in different intensity, and then the gas get into the showcase interior through the inlet.

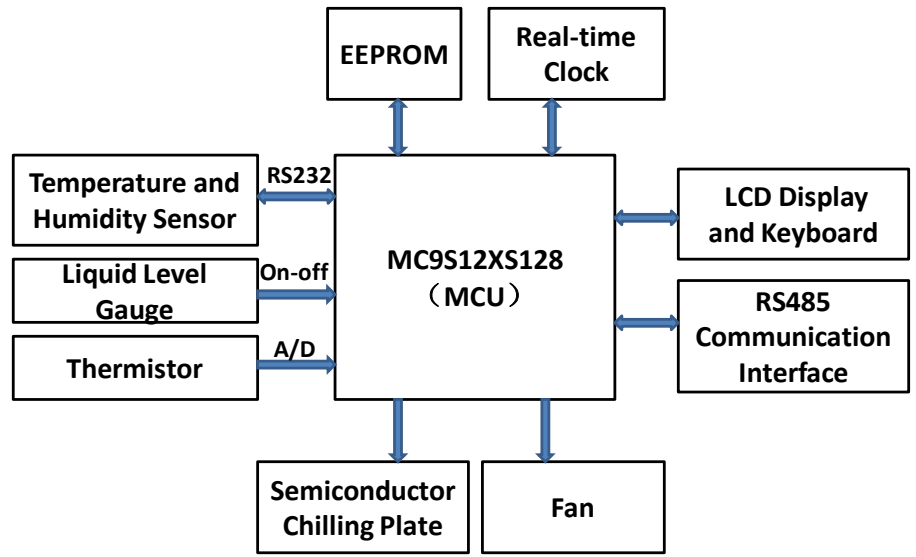

Fig.3 Hardware schematic diagram of humidistat 
The system not only realizes the function of temperature and humidity control, but also has a good man-machine interactive contact surface. You can set the desired humidity control target, the upper and lower limits for humidity, etc. through the man-machine interactive contact surface. Meanwhile, the system can communicate with the repeater through the RS485 communication interface, and the current temperature and humidity measurement data, humidity control target and the upper and lower limits for humidity will be uploaded to relay for realizing the unified management.

The picture of humidistat is showed in Figure 4.

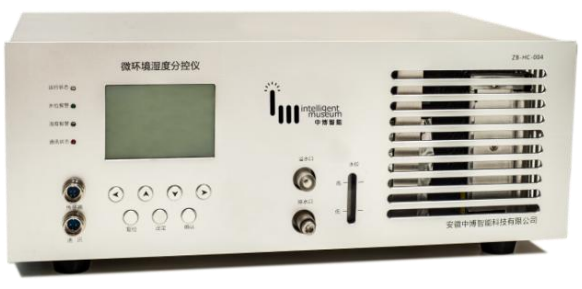

Fig.4 Picture of humidistat

\section{Application}

Microenvironment regulation system realizes the automatic control of the showcase microenvironment according to the needs of cultural relics with the science and technology. The constant temperature and humidity equipment, air purification equipment, lighting control equipment and wireless security equipment uploaded the parameters to the microenvironment intelligent monitoring platform through the repeater. The system established a net in the microenvironment. Network architecture of the Microenvironment regulation system is shown in Figure 5. Microenvironment intelligent monitoring platform as the host can be connected to several repeaters through the wireless network, and manage these devices. Each repeater has its own IP address, and the museum maintenance personnel can monitor the state of all the showcase microenvironment in the museum through the microenvironment intelligent monitoring platform. The repeater not only can upload data to intelligent monitoring platform, but also can connected with its subordinate equipments through RS485 communication interface, and access the relevant data from these subordinate equipments. And then the repeater will upload the relevant data to the intelligent monitoring platform for the observation of the museum maintenance personnel.

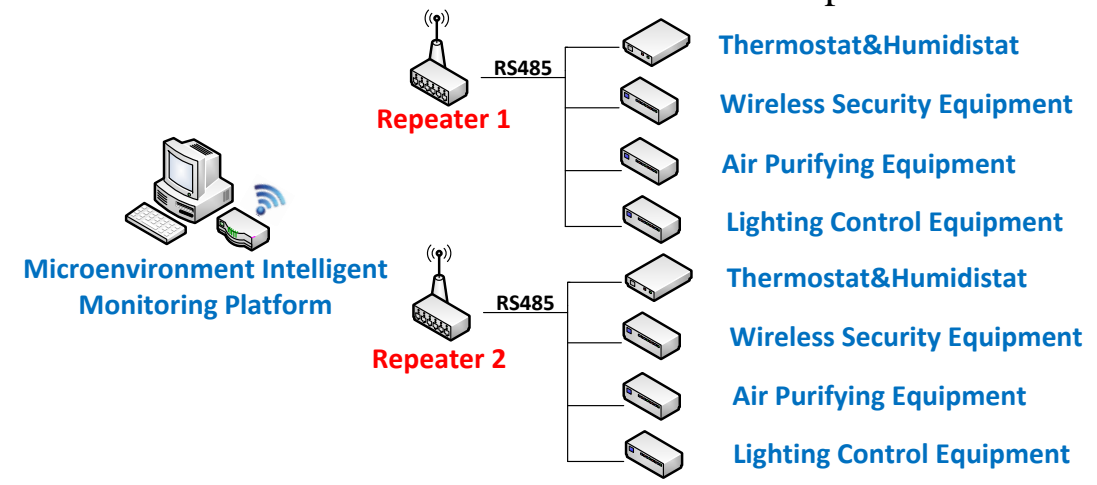

Fig.5 Network architecture of the Microenvironment regulation system

Showcase microenvironment intelligent monitoring platform interface is shown in Figure 6(a). In Hall 1, the 1st showcase as an example, the interface not only can display the current temperature, current humidity, air quality parameters (including formaldehyde, PM2.5, TVOC, carbon dioxide, sulfur dioxide, nitric oxide, nitrogen dioxide, ozone), illumination, color temperature, ultraviolet radiation and other parameters of the showcase microenvironment, but also can view the parameter variation curve over time (temperature curve in the figure). For the museum maintenance personnel, it is very convenience to observe the changes in each parameter of the showcase. The system has been steadily applied in the Palace Museum. Figure 6(b) is the picture of exhibition in the Meridian Gate of the Palace Museum. 


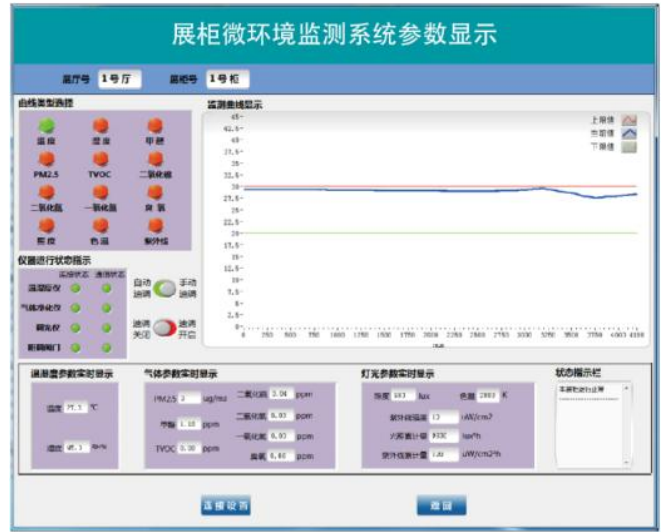

(a)

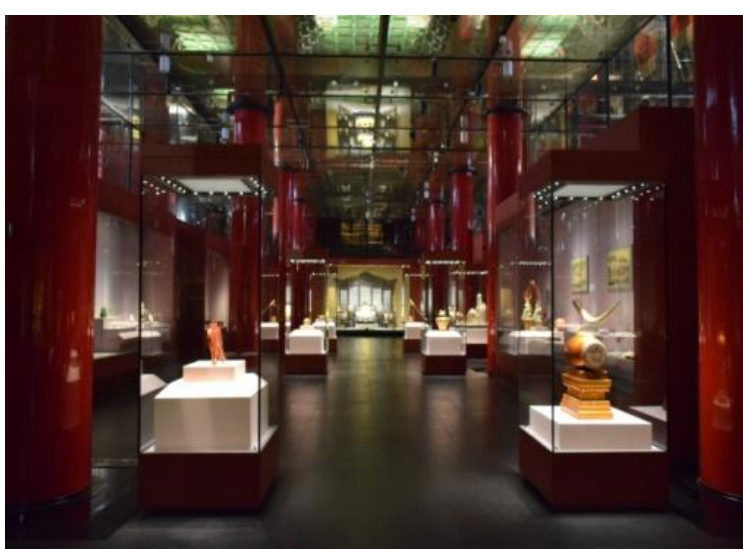

(b)

Fig.6(a) Showcase microenvironment intelligent monitoring platform interface

Fig.6(b) Picture of exhibition in the Meridian Gate of the Palace Museum

\section{Summary}

Cultural relics is the product of history, which represents a variety of information about economic, political, military, arts and crafts, science and technology in the specific historical period, and protecting the cultural relics is our duty [2]. Through establishing the microenvironment intelligent control system which is on the basis of integration and free maintenance, the system provides a good guarantee for the reasonable display and conservation of the cultural relics. The microenvironment regulation system has been applied in the Palace Museum. After testing, the system runs well. The system provides a reasonable solution for the cultural relics protection cause, and it promotes development and utilization of information resources. The system make the cultural relics provide more services for the development of human beings for a long time, and it make a contribution to the cause of the cultural relic protection.

\section{Acknowledgement}

Thanks to the support of the key projects of scientific and technological achievements transformation and industrialization in Anhui Province: IMICZ2015004 and the Palace Museum.

\section{References}

[1] Monitoring the Museum Environment. Scottish Museum Council Factsheet. (1996) 1-7

[2] SUN Cuilian, The Experimental Study on Microclimate Controlling Technology of Culture Relic Storage and Display Case (D), Beijing University of Technology. (2005)

[3] J.Ault, S.A.Klein, D.T.Redindl, J.Guay. Indoor Environmental Control: Review of Current Recommendations and Survey of Condition at the Chicago Field Museum. (2001)

[4] CHEN Suying, ZHAO Zuoyong, The Collection of Artifacts Microclimate Protection Methods and Strategies (J), Art of China. (2012) 71-76

[5] Charles S. Tumosa, Marion F. Mecklenburg, David Erhardt. A Discussion of Research on the Effects of Temperature and Relative Humidity on Museum Objects . New York Allworth Press. (1997) $130-132$

[6] Helen Alten, How Temperature and Relative Humidity Effects on the Mechanical and Chemical Stability of Collections. ASHRAE Journal. (1999) 77-82

[7] Camuffo D, Giovanni Sturaro, Antonio Valentino. Showcase: a really effective mean for protecting artworks. Thermochimica Acta. (2000) 65-77 